CuPAUAM. $15-1988$

\title{
CERAMICA DE CUERDA SECA EN UN DOCUMENTO DE LA GENIZA DE EL CAIRO
}

\author{
FERNANDO VALDÉS FERNANDEZ \\ Universidad Autónoma de Madrid. \\ A MANUEl OCAÑa JimÉnez, \\ maestro, amigo, hombre ejemplar. In memoriam.
}

\section{Resumen}

El presente artículo trata de la posibilidad de que la cerámica andalusí conocida con la polémica denominación de tipo "cuerda seca", fuera aludida en su época con el término árabe mujfiyat.

\section{Summary}

The matter of this paper rules on the possibility that the andalusian pottery commonly known "cuerda seca", were denominated at his time with the arabian word mujfiyat.

Con bastante frecuencia se otorga en los medios arqueológicos a determinadas manufacturas una denominación convencional poco o nada relacionada con la suya original, que suele permanecer desconocida. Es el caso de varios tipos de cerámicas andulusíes cuyo nombre más conocido suele tener relación con alguno de los rasgos de su apariencia física o, en la mejor de las ocasiones, con algún documento histórico donde se las menciona, generalmente de un modo ambiguo.

Un caso paradigmático viene a ser el de la llamada cerámica de cuerda seca, cuyas primeras producciones conocidas están documentadas en la Península Ibérica y, hoy por hoy, no antes del siglo XI (1).

(1) Casamar, M. y Valdés, F. (1984), a pesar del cúmulo de hallazagos producido en los últimos años, seguimos considerando válida la opinión puesta de manifiesto en ese trabajo y, posteriormente, en VALDÉs, F. (1985, pp. 289-304). Existe la posibilidad, teórica, de recuperar fragmentos de cuerda seca, procedentes en la Península o del Oriente Medio, cuya fecha puede fijarse con seguridad en el siglo X, pero hasta el momento, nadie ha conseguido probarlo univocamente por vía estratigráfica. 
El nombre de esta peculiar forma decorativa lo empleó por primera vez el erudito sevillano J. Gestoso y Pérez, quien lo tomó del Libro de Cargo y Data de la catedral y de Sevilla (CASAMAR, y VALDÉs, 1984, 383 y VALDÉs, 1985, 293), y fue ampliamente aceptado y divulgado por otros tratadistas posteriores, especialmente por M. Gómez-Moreno (GóMEZMORENO, 1924, 26). A partir de ese momento, el término cuerda seca ha pasado a formar parte del léxico de arqueólogos y ceramistas, a pesar de la dificultad que entraña su interpretación literal para los hispanohablantes y, sobre todo, para aquellos especialistas que, sin serlo, han pretendido traducir literalmente el término a otras lenguas, con resultado harto confuso. Quizás todo hubiera sido más fácil si, como opinia J. Aguado (AGUADO, 1983, 43), en vez de cuerda se hubiera hablado de línea al aludir al trazo oscuro, sin vidriar - seco-, origen del término.

Por los demás, no resulta fácil asegurar si algunos tipos cerámicos que, en términos de método arqueológico, se consideran definibles y bien definidos lo estaban tan claramente en la terminología de sus creadores. La documentación escrita llegada a nuestras manos no da pie a demasiadas alegrías, tanto en lo que se refiere a las técnicas como en aquello que atañe it las formas y a su uso (VALDÉs, 1985, 80-81).

El caso de la cuerda seca no es diferente de los demás, aunque hayamos de suponerle especifidad terminológica a técnica tan precisa. En ayuda de esta suposición parece venir un documento procedente de la Genizá de El Cairo (2), fechado en el mes hebreo de nissan del año 1548 ( = 1137 d. C.).

Se trata de una carta parcialmente publicad. por S. D. Goitein (GorteIN, 1956, 395-398 y 403-405), enviada desde algún punto de la Península Ibérica por un judío egipcio a su

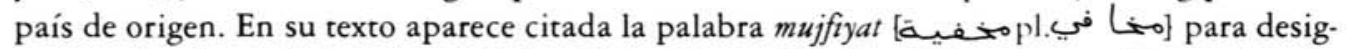
nar un tipo de cerámica característico del occidente islámico, del cual se enviaban ocho piezas desde al-Andalus a Egipto (GoITEIN, 1967, 111 y 422, nota 76).

Ahora bien, existen ciertas diferencias de matiz a la hora de abordar el sentido exacto de ese término. Mientras que R. Dozy admite su origen magrebí y lo define como «....sorte de pot et jarron (Tunis)... De là l'esp. alfomia, sorte de plat ou d'écuelle» (DOZY, 1927, 387-388), Goitein parece considerarlo, más bien, como un tipo de cerámica que como una forma concreta: The mukhfiyat pottery, eight pieces of wich were sent fronm Spain to Egypt in $1137 \ldots$ was a speciality of the Muslim West (GoITEIN, 1967, 111 y 422, nota 76).

Sea cual sea la interpretación a la que hayamos de conceder más crédito cabe intentar un acercamiento desde la estricta óptica arqueológica. El meollo de la cuestión reside en saber qué tipo de cerámica fabricada en al-Andalus podía ser lo suficientemente apreciada en Egipto, en la primera mitad del siģlo XII, como para justificar un envío de ocho piezas, sabida la escasa oferta de producciones alfareras de calidad de origen andalusí y, por el contrario, la riqueza y variedaci de las manufacturas egipcias contemporáneas.

(2) Goiteın, S. D. (1966a), (1966b) y 1966(c), pág. 282. A pesar de haberse encontrado en Egipto, muchos de esos documentos proceden de otros lugares. El orden de frecuencia es: 1. Norte de Africa, Sicilia y España; 2. Palestina y Siria; 3. Iraq; 4. Yemen e India; 5. Bizancio. Apenas se ha conservado ningún material referente a países cristianos del occidente europeo. Por ln que respecta a su cronologia, pocos pertenecen al siglo X y a la Baja Edad Media -1250-1500_. La mayoría se datan en época fatimi y ayyubi. 
Por lo que se refiere a la Península Ibérica, a pesar de que existen numerosas variedades cerámicas, ninguna alcanza, desde un punto de vista técnico, la categoría de las piezas producidas en Egipto durante el siglo XI y, mucho menos, durante el XII. Los productos de vidriado estañifero y pintura sobre cubierta, bien documentadas allí por esas fechas (3), no se conocían en al-Andalus o, en el mejor de los casos, acababan de hacer su primera y muy imperfecta aparición. Es el caso de las lozas doradas (4).

Por los demás, dejando al margen las cerámicas de cuerda seca, a las que ya hemos hecho mención más arriba, los objetos decorados con la técnica conocida como verde y manganeso no poseen un grado de calidad comparable al de los egipcios contemporáneos y, a esas alturas, estaban muy superados técnicamente (VALDÉs, 1985, 266-282, 1986).

Tampoco las piezas andalusíes de menor calidad estética eran capaces de superar a sus coetáneas fabricadas en las márgenes del Nilo. Sin despreciar la calidad de los alfareros peninsulares, es obligado reconocer la finura alcanzada por los artesanos fatimíes a la hora de crear piezas como los famosos filtros (OlMER, 1932-1935/40 y SCANLON, 1968, 9-16).

Resulta, pues, difícil imaginar que un viajero se tomase la molestia de enviar a Egipto ocho vasijas de cerámica andalusí capaces de suponer un auténtico regalo para alguien habituado a moverse entre objetos de mejor técnica y calidad estética más depurada (5). Sólo la vajilla de cuerda seca, más atrayente por su colorido abigarrado que por lo avanzado de su proceso de producción, podía resultar un obsequio capaz de agradar al destinario o, de tener como destino final el mercado, a sus posibles clientes.

La aparición de numerosos fragmentos de cuerda seca andalusí en el transcurso de los primeros arqueológicos llevados a cabo de Fustat, vendría a subrayar todo lo dicho y permitiría identificar la mujfiyat de la carta de 1137 con la vajilla decorada a la cuerda seca.

Con sólo los elementos enumerados, difícilmente habríamos podido llegar a ninguna conclusión, si amén de la hipotética identificación propuesta, no poseyéramos otra evidencia más concluyente.

Es conocida, desde los primeros trabajos de excavación en Fustat, la existencia de un numeroso lote de fragmentos de cuerda seca depositados hoy en el Museo de Arte Islámico de El Cairo (6). Solo recientemente, estos fragmentos han sido correctamente clasificados co-

(3) Las piezas con decoración pintada sobre cubierta debieron aparecer en el mundo islámico después del 825 o, quizás, del 850. Cf. Whitehouse, D. (1970), pp. 38.39 y (1979), pág. 59.

La imitación de cerámicas andalusies son en Egipto un fenómeno constatable a partir de los últimos años del siglo X o primeros del XI (Philon, H., 1980, pp. 35-38, fig. 120, lám. IV.c), aunque su repercusión estilística sea superior a la técnica, como parecen demostrarlo algunos cortos fragmentos, fabricados con vidrío estañifero, en los que la influencia - directa o indirecta - de al-Andalus nos resulta evidente. Cf. GrUBE, E. J. (1976), Pp. 120-123, fig. 77; JEN. KINS, M. (1975), pág. 106 y Philon, H. (1980), pág. 38, no. 116, lám. V.A. y no. 125.

(4) Para el problema de los orígenes de la loza dorada en al-Andalus cf. VALDES, F. (1982/83) y (1985), pp. 311-313; Navarko Palazon, J. (1986).

(5) En esa época no eran tampoco raras en los mercados de Fustat las piezas importadas de China, cuyo nivel técnico era muy superior a los productos andalusies e, incluso, a los propios egipcios. Cf. SCANLON, G. T. (1970); GYLleNSVARD, B. (1973) y (1975).

(6) Bahgat Bey, A. (1922), lám. 1. Este autor las fechó, sin mayores precisiones, en el siglo X. Varios ejemplos más, de igual origen, fueron analizados por H. PHILON (1980, pág. 38, figs. 110-111, lám. V.C.) estilisticamente y considerados de origen español. 
mo inequívocamente andalusíes y fechados entre el siglo XI y el año 1169 , cuando la ciudad fue quemada y destruida (CASAMAR, 1980-81 y JOMIER, 1977). Es, pues, evidente que esta variedad cerámica - arcaica en su técnica - era apreciada en el mercado egipcio y objeto de una cierta demanda comercial, al menos en su variedad total (7).

Una última cuestión quedaría por dilucidar, una vez aceptada la identificación provisional del término mujfiyat con las piezas de cuerda seca peninsulares del tipo de las halladas en Fustat. ¿En realidad dicho término define a una técnica decorativa o, como quiere R. Dozy, se refiere a la forma concreta de un objeto o de un tipo de objetos?

La contestación es difícil, porque, incluso, la definición de este autor posee dos acepciones bien definidas. En la primera, utilizada en Túnez, mujfiyat aparece como «...sorte de pot et jarron» (DOZY, 1927, 387-388), es decir, una forma cerrada; en la segunda, la del derivado español almofia, es una "sorte de plat où d'écuelle» (Ibid), es decir, una forma abierta.

Pueden darse tres posibles soluciones:

1) El envío del judío egipcio lo formaban ocho piezas de una determinada forma conocida como mujfiyat, con independencia de que su apariencia decorativa, argumentable en términos arqueológicos, se debiera al empleo de la técnica de la cuerda seca.

2) La palabra mujfiyat se referería a un tipo de técnica ornamental, arqueológicamente identificable como cuerda seca.

3) El término mujfiyat aludía a una técnica ornamental, pero su reiterado empleo sobre una o unas determinadas formas de vajilla acabó por designarlas, aunque su adorno no estuviese ya realizado del mismo modo.

No podemos inclinarnos por ninguna de las tres opciones. A falta de una publicación exhaustiva de los materiales arqueológicos descritos y desconociendo la proporción de formas cerradas y abiertas, hemos de dejar la cuestión sin resolver. Sí tenemos por seguro, en términos de Arqueología, que los objetos enviados de al-Andalus a El Cairo en 1137 estaban ornamentados, con casi total seguridad, a la cuerda seca y ahí residía su mayor motivo de aprecio en el mercado egipcio. El resto deberán aclararlo, si encuentran forma de hacerlo, los especialistas en filología árabe.

(7) En relación con la diferencia existente entre los tipos de cuerda seca parcial y total cf. CASAMARz, M. y VAL. DÉs, F. (1984), pág. 384 y VALDÉs, F. (1985), pág. 297. 


\section{Bibliografia}

AGUAdO, J. (1983): "La cerámica hispanomusulmana de Toledo». Madrid.

BaHgat, BeY, A. (1922): "La Céramique Egiptienne de l'époque musulmane. Basilea.

CASAMAR, M. (1980/81): "Lozas de cuerda seca con figuras de pavones en los museos de Málaga y El Cairo". Mainake, 2-3. 203-209.

CASAMAR, y VALDÉS, F. (1984): "Origen y desarrollo de la técnica de cuerda seca en la Península Ibérica y en el Norte de Africa durante el siglo XI". Al-Qantara, 5. 383-404.

DOZY, R. (1927): Suppléments aux Dictionnaires Arabes. T. I. Leiden-París. 2. ${ }^{a}$ edición.

GoITEIN, S. D. (1956): "Glimpses from the Cairo Geniza on naval warfare in the Mediterranean and on the Mongol invasion”. En Studi Orientalistici in Onore di Giorgio Levi della Vida. T. I. Roma. 393-408.

GorteIn, S. D. (1966a): "The mentality of the Middle Class in Medieval Islam». En Studies in Islam History and Institutions. Leiden, 246-254.

GoiteIN, S. D. (1966b): «The Working People of the Mediterranean Area during the High Middle Ages". En Studies in Islamic History and Institutions. Leiden. 255-278.

GoITEIN, S. D. (1966c): «The Documents of the Cairo Geniza as a Source for Islamic History». En Studies in Islamic History and Institutions. Leiden. 279-295.

GoITEIN, S. D. (1967): A mediterranean Society. The Jewish Communities of the Arab World as Postrayed in the Documents of the Cairo Geniza. I. Economic Foundations. University of California Press.

Gómez-Moreno, M. (1924): Cerámica Medieval Española. Barcelona.

Grube, E. J. (1976): Islamic Pottery of Eighth to the Fifteenth century in the Keir Collection. Londres.

GYLLENSVARD, B. (1973): "Recent finds of Chinese ceramics at Fustat. I". Bulletin of the Museum of Far Eastern Antiquities Stockbolm, 45, 91-119.

GYLLENSVARD, B. (1975): "Recent finds of Chinese ceramic at Fustat. II». Bulletin of the Museum of Far Eastern Antiquities Stockbolm, 47, 93-117.

JENKINS, M. (1975): «Western Islamic influences on Fatimid Egyptian Iconography». Kunst des Orients, 10, 91-107.

JOMIER, J. (1977): «al-Fustat». EI 2.a ed. 979-981.

NaVARro Palazón, J. (1986): “Murcia como centro productor de loza dorada». En La Cerámica Medievale nel Mediterraneo Occidentale. Florencia, 129-143.

Olmer, P. (1932): Catalogue Générale du Musée Arabe du Caire. Les Filtres de Gargoulettes, El Cairo.

Olmer, P. (1935/40): "Le décor des filtres de gargoulettes de l'Egypt musulmane». En Mélanges Maspero, III, 33-39.

Philon, H. (1980): Early Islamic Ceramics. Ninth to late Twelfth Centuries. Islamic Art Publications.

SCANLON, G. T. (1968): "Ancillary Dating Materials from Fustat". Ars Orientalis, 7, 9-16.

SCANLON, G. T. (1970): «Egypt and China: Trade and Imitation». En Islam and the Trade of China. Oxford y Filadelfia, 81-95.

VALDÉS, F. (1982/83): "Al-Idrisi y los orígenes de la loza dorada en la Península Ibérica». Awraq, 5-6, 243.245.

VAldÉs, F. (1985): La Alcazaba de Badajoz, Madrid.

VALDÉS, F. (1986): “La cerámica del tipo verde y manganeso: aparición, difusión y primeras influencias». En Actas del I Congreso de Arqueología Medieval Española, Zaragoza, 269-281.

Whitehouse, D. (1970): «Some Chinese and Islamic Pottery from Siraf». En Pottery and Metalwork in T'ang China. Colloquies on Art and Archaeology in Asia. No. 1. Londres.

WhitehOUSE, D. (1979): “Islamic glazed pottery in Iraz and the Persian Gulf: The ninth and tenth centuries". Annali Istituto Orientale di Napoli. 39. N.S., 29, 45-61. 